Nloman 2015, 33(1), 93-100

Revista de Psicologia, Ciències de l'Educació i de l'Esport

ISSN: 1138-3194

Copyright $\odot 2015$

www.revistaaloma.net

\title{
El pacient agredeix el professional? La violència laboral de tipus II: un fenomen existent
}

\author{
Cristina Vidal-Martí1,2 i Carles Pérez-Testor ${ }^{2,3}$ \\ 'Fundació Pere Tarrés i F. d'Educació de Universitat de Barcelona \\ ${ }^{2}$ Grup de Recerca de Parella i Família (URL) \\ ${ }^{3}$ Univ. Ramon Llull (URL). FPCEE Blanquerna i IUSM Vidal Barraquer
}

Rebut: 25-10-2014

Acceptat: 27-3-2015

El pacient agredeix el professional? La violència laboral de tipus II: un fenomen existent

Resum. Aquest article de caràcter descriptiu té la finalitat d'exposar un fenomen existent com és la violència laboral. La violència laboral, un constructe amb pocs anys d'estudi, afecta totes les professions i les diferents categories professionals. S'estructura en cinc apartats. En el primer, es defineix pròpiament l'objecte d'estudi; en el segon, les dades de l'abast del fenomen; en el tercer, la tipologia; en el quart les teories que expliquen el perquè es produeix i en l'últim els factors de risc.

Paraules clau: agressió, professionals, violència laboral, vulnerabilitat

The patient attacks the professional? Type II workplace violence: a real phenomenon

Summary. This descriptive article aims to call attention to the real phenomenon of workplace violence. Workplace violence as a concept has been the object of study for only a few years, but it affects all professions and professional categories. The article is structured in five sections. The first defines the object of study; the second features data on the dimensions of the phenomenon; the third is a classification; the fourth details the theories that offer explanations as to why it occurs; the final one discusses risk factors.

Keywords: aggression, professionals, workplace violence, vulnerability

Correspondència

Cristina Vidal-Martí

Cristina Vidal-Martí

Fundació Pere Tarrés

C/ Carolines, 10

08012 Barcelona

934101602

cristinavidal.vm@gmail.com 


\section{Introducció}

En els últims 25 anys, ha augmentat considerablement el nombre de publicacions relacionades amb la violència en l'entorn de treball. La violència laboral, tal com s'anomena en la literatura científica, començà a estudiar-se com a fenomen social arran de l'increment d'incidents i de la sensibilitat d'organismes internacionals (Toscano \& Weber, 1995; OSHA, 1996; NOHSC,1999; OMS \& OIT, 2002; Krug, 2002).

Els primers estudis daten dels anys setanta, però, no serà fins vint anys més tard que s'inicia la seva investigació centrant-se inicialment en l'abast del fenomen, posteriorment en els factors de risc i, a partir de segle XxI, en l'avaluació dels programes preventius (Ekblom, 1970; Bulatao \& VandenBos,1996; Gerberich et al., 2004; Paoli \& Merllié, 2003; Eurofound, 2012).

L'objectiu d'aquest article és presentar el fenomen de la violència laboral de tipus II. Un fet present en la nostra societat de poca visibilitat social tot i les seves repercussions en els professionals i en les organitzacions.

Per a aconseguir aquest objectiu, definirem el constructe, exposarem les dades en relació a a aquest fet, la tipologia, els models explicatius i, finalment, explicarem els factors de risc perquè, d'aquesta manera, podrem conèixer i comprendre per què es produeix el fenomen i establir, com a conseqüència, mesures corresponents de prevenció.

\section{Conceptualització de la violència laboral}

Definir la violència laboral és una tasca complexa per la multidimensionalitat del constructe, el gran nombre de factors i agents implicats, la quantitat de disciplines que aborden el fenomen i la complexitat del context en què es desenvolupa (Warshaw \& Messite, 1996; Wynne, Clarkin, Cox \& Griffiths, 1997; Chappell \& Di Martino, 2006; Van De Griend \& Messias, 2014). Tota definició està mediatitzada per factors culturals i temporals; i la violència laboral, també, fet que agreuja encara més la seva conceptualització (Gill, Bowie \& Fisher, 2002).

L'Occupational Safety and Health Administration (OSHA) (1996) va ser un dels primers organismes a definir la violència laboral. Segons aquesta institució sanitària, la violència laboral s'entén com «un assalt psicològic, una conducta amenaçadora o un abús verbal que succeeix en un lloc de treball» (p. 4).

Amb un accent lleugerament diferent, la National Occupational Health and Safety Commission (NOHSC) (1999) definí la violència laboral com «l'intent o l'exercici realitzat per una persona amb la finalitat de causar lesions a un treballador; això inclou qualsevol declaració com a amenaça real, fet que suposa per al treballador creure que està en perill»(p. 1).

L'OMS \& l'OIT (2002), amb la finalitat de clarificar i presentar unitàriament una definició, estableixen que «la violència laboral està constituïda per incidents en els quals la persona pateix abusos, amenaces o atacs en circumstàncies relacionades amb el seu treball -inclosos els viatges d'anada i tornada- que posin en perill, implícitament o explícitament, la seva seguretat, el seu benestar o la seva salut» (p. 3).

Tres anys més tard, Plante (2005), amb la finalitat de consensuar i englobar les definicions realitzades fins al moment, n'estableix una de nova:

(... ) la violència en el lloc de treball com qualsevol incident relacional que implica la intervenció d'individus o de grups en circumstàncies relacionades amb el treball que comporten conseqüències negatives per a la seva seguretat $i$ la seva dignitat. En principi, la violència laboral no inclou els conflictes simples i aïllats que es resolen a través de la negociació i el diàleg sinó els hiperconflictes i les agressions, l'assetjament psicològic, moral o sexual, l'abús de poder i també les amenaces amb armes, els robatoris, els homicidis i els suïcidis en el treball (Plante, 2005, p. 6).

L'any 2006, Chappell \& Di Martino corroboren la definició que van realitzar l'any 1998 i en la qual introduirren un nou element: qui és l'agent causal. Aquests autors conceptualitzen «la violència en el lloc de treball com qualsevol incident en el qual un treballador és abusat, amenaçat o bé agredit per un membre del públic: pacient, client o company de treball» (Chappell \& Di Martino, 2006, p. 12).

Tot i l'esforç realitzat per organismes internacionals i pels autors, a dia d'avui no hi ha una conceptualització consensuada de la violència laboral.

\section{Magnitud del fenomen}

L'OMS \&OIT (2002) afirma que la violència laboral afecta tots els països independentment del seu nivell de riquesa. La incidència d'aquest fenomen és desigual i «en els països en els quals és un assumpte de debat públic, les dades registrades són superiors respecte als altres» (Merecz, Rymaszewska, Móscicka, Kiejna \& Jarosz-Nowak, 2006, p. 442).

La violència en el lloc de treball afecta pràcticament tots els sectors i categories professionals (Nordin, 1993). No obstant això, hi ha ocupacions que presenten una afectació més elevada respecte d'altres. VandenBos \& Bulatao (1996) van establir que els professionals de la banca, del transport, la policia i els cossos de seguretat, els venedors, els mestres i professors, els taxistes i els professionals que treballen amb malalts $i$ amb persones amb alts nivells d'estrès o situacions de malestar són els més afectats. Tot i que hi ha estudis que avalen que aquestes professions continuen essent de risc (Neuman \& Baron, 1998; OIT, 1998), aquest escenari no és estàtic perquè la societat està en evolució i en canvi continu; i això significa que les ocupacions que fa uns quants anys no eren de risc, ho poden arribar a ser en un futur immediat.

Anys més tard, Bowie (2002) ratificava que la violència laboral és un fenomen que es produeix en totes les professions i col-lectius professionals i alertava de l'augment en els últims deu anys del fenomen, atribu- 
int-lo als canvis en les polítiques socials: una disminució de les prestacions, una manca d'ajudes socials i serveis comunitaris, uns processos de desinstitucionalització per a persones amb malaltia mental greu i per a menors en situacions de risc sense l'acompanyament i el suport necessaris. Segons aquest investigador, l'increment de la violència estructural en la societat es relaciona de manera directa amb la violència laboral i, a la vegada, qüestiona la interdependència dels dos fenòmens.

Avui en dia es desconeix l'abast real de la violència laboral, malgrat l'increment d'estudis. Les deficiències metodològiques, la multiplicitat de variables a estudiar i la indefinició del concepte no permeten conèixer amb precisió la magnitud del fenomen (Berrios \& López-Zafra, 2005; Rumsey, Foley, Harrigan \& Dakin, 2007; Cantera, Cervantes \& Blanch, 2008). Tal com apunten Cooper \& Swanson (2002), el més probable és que les dades disponibles tan sols configurin la punta de l'iceberg, com succeeix amb els altres tipus de violència.

Tanmateix, hi ha dos estudis realitzats per organismes internacionals que s'han interessat a estudiar l'abast del fenomen. El primer, elaborat per l'OIT (1998), posa de manifest que la incidència anual d'homicidis per motius de treball a Anglaterra va ser de 1,41 per 100.000 treballadors. Aquest mateix estudi comparà aquesta xifra amb la d'Austràlia, presentant un resultat lleugerament superior, amb una taxa de 4,88, i inferior a la dels Estats Units, amb un 8,95. Els autors de l'estudi expliquen el valor del fenomen americà per la permissibilitat d'armes en la seva societat.

El segon estudi és el que realitzà la Fundació Europea per a la millora de les condicions de vida i de treball. Segons les últimes dades, publicades a través del cinquè estudi (Eurofound, 2012), el 2 \% dels treballadors de la Unió Europea van ser víctimes de la violència física en el seu lloc de treball i l'11 \% expressà haver experimentat abús verbal en el seu entorn laboral. L'estudi també establí que 1'1 \% dels treballadors expressà haver patit assetjament sexual i el $4 \%$, intimidació. En relació als sectors, el del transport (20\%) i el de la salut (23\%) són el que expressaren índexs més elevats; i per països, Finlàndia (21 \%) i Àustria (22 \%) són els que presenten percentatges més elevats de violència laboral.

Aquestes dades evidencien que la violència laboral és un fenomen present en la societat; tot i tenir poca visibilitat, té incidències en els diferents sectors professionals.

\section{Taxonomia de la violència laboral}

California Division of Occupational Health and Safety (Cal/OSHA) (1995) va establir una taxonomia per a conceptualitzar la violència laboral. Segons aquest organisme, la violència laboral es classifica en base a l'agent que exerceix la violència i estableix tres tipus de violència: violència laboral de tipus I, II i III.

La violència laboral de tipus I es caracteritza perquè la persona que porta a terme l'acció violenta no té cap relació legítima amb qui la pateix. Una de les situacions més pròpies d'aquest tipus de violència és quan hi ha la intenció de robar. Els professionals amb més risc de patir aquest tipus de violència són, entre altres, els següents: banquers, botiguers, treballadors de magatzems, persones que treballen amb objectes de valor, personal de gasolineres, taxistes.

La de tipus II es defineix quan hi ha un grau de relació professional entre la persona que causa l'acte violent i la víctima. Segons Cal/OSHA (1995), les conductes violentes es produeixen mentre s'ofereix el servei, i els professionals amb més risc de patir-les són aquests: persones que intervenen en serveis de seguretat pública, conductors d'autobusos, personal sanitari i de serveis socials, mestres, docents i professors, venedors o altres treballadors del sector públic o privat que ofereixen serveis professionals.

La de tipus III es caracteritza perquè la persona que realitza els actes violents té alguna implicació o relació laboral amb un company, que també és treballador, o amb el lloc on es produeix l'acte. Hi ha distintes situacions en què aquest tipus de violència és freqüent, com, per exemple, quan es produeix entre un treballador que és víctima i un excompany de treball. Tanmateix, la situació més freqüent és aquella en què un treballador exhibeix una conducta violenta envers un altre company del mateix rang i justifica l'acció com una manera de buscar venjança o d'exercir la justícia pel seu compte.

Aquest article se centra en la violència laboral de tipus II, un tipus de violència laboral en què hi ha una relació entre qui fa l'acció violenta i el professional, que n'és víctima.

\section{Teories explicatives de la violència laboral de tipus II}

Després d'haver presentat l'objecte d'estudi, els diferents tipus de violència i la seva incidència, en aquest apartat ens centrarem a explicar el perquè es produeix el fenomen. Hi ha diferents teories explicatives; tanmateix, és a partir de dues d'aquestes que n'apareixen d'altres. Aquestes dues teories són la teoria de la violència i l'agressió en el treball, de Neuman \& Baron (1998), i el model interactiu, de Chappell \& Di Martino (2006).

La teoria de la violència i l'agressió en el treball, de Neuman \& Baron (1998), consisteix a explicar el fenomen en relació als factors socials i situacionals; per contra, Chappell \& Di Martino (2006) entenen que la violència no és causada per dos únics factors, sinó per la interacció de riscs potencials.

El nostre mode d'entendre, el model interactiu de Chappell \& Di Martino (2006) desperta un interès especial perquè facilita la comprensió del fenomen, permet identificar els possibles factors de risc i, a la vegada, ajuda a predir la situació de violència.

Segons el model interactiu, els factors de risc comprenen tant comportaments individuals com de l'entorn. En la figura 1, hi ha una representació gràfica del 
Figura 1. Representació gràfica del model de Chappell i Di Martino (2006)

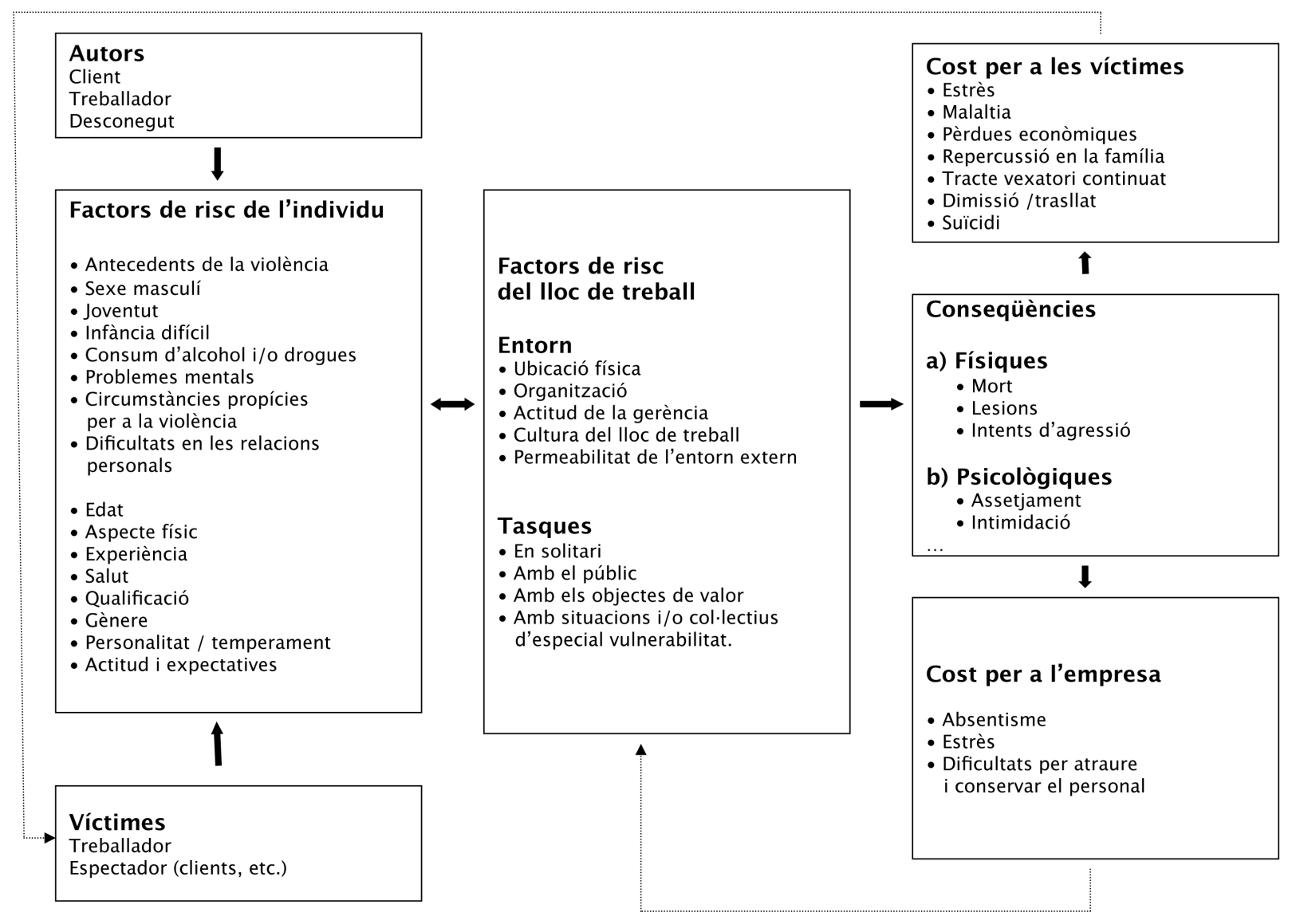

model interactiu proposat per aquests autors. Tal com s'observa, els factors s'estructuren en funció de dos contextos: el de l'individu i el del lloc de treball; i, a la vegada, aquest segon es divideix en dos: un associat a l'entorn del treball i un altre a les tasques realitzades.

Els factors de risc individual són factors relacionats amb les variables sociodemogràfiques (gènere, edat, grau d'escolaritat i estat civil), els trets de personalitat, la història de vida, les condicions de salut i les característiques individuals relacionades amb el treball, com ara l'experiència i el nivell de capacitació entre altres. Chappell \& Di Martino (2006) van considerar que ser home, jove, tenir un historial de comportament violent, haver tingut una infància difícil, patir una malaltia mental severa, tenir dificultats per relacionar-se amb les altres persones i tenir accés a les armes -ja siguin de foc o d'un altre tipus- eren factors d'alt risc individual de l'autor que exercia l'acte.

En relació al lloc de treball, Chappell \& Di Martino (2006) estableixen dos tipus de factors de risc: els propis de l'entorn de treball i els vinculats a les tasques realitzades.

Els cinc factors de risc pròpiament vinculats a l'entorn del treball són aquests: ubicació física, organització, actitud de la gerència, cultura del lloc de treball i permeabilitat de l'entorn extern.

El primer factor de risc en l'entorn del treball és la ubicació física. Treballar en zones amb un alt risc d'índex de criminalitat facilita l'aparició d'actes violents.
Aquesta mateixa circumstància succeeix en el lloc de treball. Els entorns amb economies inestables i zones deprimides són més proclius a l'aparició de la violència laboral.

L'organització és el segon factor de risc. Una organització que facilita la incertesa i provoca inseguretat de manera continuada en el treballador perquè no sap si confien en ell, és un factor afavoridor de la violència laboral. Els canvis continus de torn en són un altre.

Els estils de direcció rígids, autoritaris i que fomenten la intimidació com a estratègia de lideratge (OMS \& OIT, 2002) són factors de risc de la violència en el lloc de treball. Segons Chappell \& Di Martino (2006), un determinat estil de direcció pot arribar a ser un factor desencadenant de la violència laboral.

La cultura del lloc de treball és el quart factor de risc proposat pels autors. Alguns exemples de situacions que afavoreixen la violència laboral són aquests: una cultura organitzativa que promogui una forta i continuada pressió per incrementar la productivitat; una organització empresarial que disposi d'una plantilla inadequada de professionals per la manca de recursos humans o que realitzi reduccions de personal inesperades; canvis constants a nivell tecnològic; deficiències importants en l'aplicabilitat de les lleis laborals existents i cultura tolerant i d'acceptació de la violència.

El cinquè i últim factor de risc és la permeabilitat de l'entorn extern. Una organització empresarial condicio- 
nada excessivament per les exigències de l'entorn facilita la violència laboral perquè no permet establir els propis límits amb l'exterior (Chappell \& Di Martino, 2006).

Una vegada presentats els cinc factors de risc de l'entorn de treball, s'exposen els quatre relacionats amb les tasques laborals establerts per Chappell \& Di Martino (2006), que són els següents: treballar en solitari, estar en contacte amb el públic, treballar amb objectes de valor i treballar amb col-lectius o en situacions d'especial vulnerabilitat.

Treballar en solitari és el primer factor de risc associat a les tasques. El treball en solitari en si ja és un factor de risc i s'accentua encara més en funció del tipus de tasca que es realitza.

Hi ha un gran nombre d'ocupacions que estan en contacte directe amb el públic; el risc de violència és més alt respecte als que no ho estan i s'accentua encara més quan s'atenen persones amb malalties mentals, sota l'efecte de l'alcohol o les drogues, o en serveis percebuts com de mala qualitat o despersonalitzats per part del client o usuari.

El tercer factor és el treball amb objectes de valor. Els treballadors que desenvolupen treballs laborals en serveis on hi ha diners o objectes de valor tenen més risc de ser víctimes d'accions violentes en tenir més probabilitats de patir un assalt o bé d'altres situacions de risc en el seu lloc de treball.

L'últim factor és treballar amb col-lectius o en situacions d'especial vulnerabilitat. La violència és una conducta observada entre els treballadors que atenen persones amb vulnerabilitat i sovint es considera un risc inherent al treball perquè el professional té la creença errònia que ser víctima d'un acte violent forma part del treball exercit. És el que es coneix com la síndrome del lloc de treball. Els factors que contribueixen a augmentar el risc de violència són els trastorns psiqui- àtrics, l'abús d'alcohol i d'altres substàncies tòxiques, l'augment de la pobresa i la marginació en la comunitat, les deficiències de l'entorn on es porten a terme les activitats assistencials, la manca d'organització i planificació de les activitats, l'escassa capacitació del personal que presta serveis a aquesta població i el clima general d'estrès i d'inseguretat en el lloc de treball.

En definitiva, el model interactiu permet reconèixer amb precisió els factors de risc de la violència laboral i de manera específica els del tipus II. Una identificació dels riscos permet una avaluació i conseqüentment una planificació de l'actuació, mesura preventiva i necessària per a evitar que l'acció violenta es desenvolupi en l'entorn de treball.

\section{Factors de risc que el professional que atén persones vulnerables ha de tenir en compte}

El model de Chappell \& Di Martino (2006) possibilita distingir els factors potencials de la violència laboral en relació a dos entorns, l'individual i el del lloc de treball, dividint-los cada un en dos. En relació a l'entorn individual, es diferencia entre els relacionats amb l'autor de la conducta violenta i els dels atributs del professional, que pot ser-ne víctima. I en relació al lloc de treball, discerneixen entre els de l'entorn de treball i els de les tasques. A continuació, s'exposen cada un en la taula 1.

Tanmateix, al nostre entendre, considerem que aquest model no contempla altres factors de risc establerts per altres investigacions (Linaker \& Bush-Iversen, 1995; O'Leary-Kelly, Griffin \& Glew, 1996; Neuman \& Baron, 1989; Einarsen, 2000; Rippon, 2000; Cooper \& Swanson, 2002; Sjöström,Elder, Malm \& Beskow,2001; Beech \& Leather, 2006; Cervantes, Blanch \& Hermoso, 2010; Vidal-Martí \& Pérez- Testor,2014) que tenen una incidència notable quan és l'usuari qui exerceix l'acte

Taula 1. Factors de risc de la violència laboral de tipus II (Adaptació de Chappel i Di Martino (2006))

\begin{tabular}{|c|c|c|}
\hline Entorn & En relació a & Factors de risc \\
\hline \multirow[t]{2}{*}{ Individual } & $\begin{array}{l}\text { Autor de la conducta } \\
\text { violenta }\end{array}$ & $\begin{array}{l}\text { - Persona amb antecedents de violència } \\
\text { - Home } \\
\text { - Ser jove } \\
\text { - Haver tingut una infància difícil } \\
\text { - Tenir problemes mentals } \\
\text { - Consum de tòxics } \\
\text { - Viure en un entorn en què la violència és present i s'accepta (ús d'armes...) } \\
\text { - Dificultats en les relacions personals }\end{array}$ \\
\hline & Professional & $\begin{array}{l}\text { - Ser un professional jove } \\
\text { - Tenir una aparença física de persona jove } \\
\text { - Inexperiència laboral } \\
\text { - Patir problemes de salut (física, mental...) } \\
\text { - Baixa qualificació professional } \\
\text { - Ser dona } \\
\text { - Personalitat de tipus A } \\
\text { - Actitud rígida, poc flexible ... } \\
\text { - La resposta que dóna l'altre no respon a la seva expectativa }\end{array}$ \\
\hline \multirow[t]{2}{*}{ Lloc de treball } & Entorn & $\begin{array}{l}\text { - Treballar en barris i zones amb alt índex de violència, de criminalitat i marginalitat. } \\
\text { - Organització de treball en el qual hi ha inseguretat i incertesa } \\
\text { - Organització de treball en quề hi ha canvis de torns de manera continuada } \\
\text { - Estils de direcció rígids, autoritaris o que fomenten la intimidació } \\
\text { - Cultura del lloc de treball que: } \\
\text { - tolera i accepta la violència entre els diferents rangs } \\
\text { - s'exerceix una pressió per augmentar la productivitat (augmentant el nombre d'usuaris atendre, } \\
\text { nombre de publicacions...) } \\
\text { - Canvis constants de tecnologia. } \\
\text { - Poca permeabilitat de l'entorn de treball extern }\end{array}$ \\
\hline & Tasques & $\begin{array}{l}\text { - Treballar sol } \\
\text { - Amb situacions o col-lectius d'especial vulnerabilitat }\end{array}$ \\
\hline
\end{tabular}


d'agressió envers el professional. A continuació, s'exposen i es justifiquen aquests sis factors de risc.

Un primer factor de risc és la manera de relacionar-se. Si una persona s'ha desenvolupat en entorns on l'expressió i l'acció violenta s'accepten i es reforcen de manera positiva, serà més probable que utilitzi la violència com una forma de relacionar-se. Aquesta manera de fer s'extrapolarà en els diferents contextos on actuï essent un d'ells el laboral (O'Leary-Kelly, Griffin \& Glew, 1996; Neuman \& Baron, 1998; Beech \& Leather, 2006).

Un segon factor és l'expressió del malestar. El malestar i la incomoditat de com es viuen les situacions estressores es poden manifestar a través de l'acció violenta i d'agressió (Linaker \& Bush-Iversen, 1995; Rippon, 2000; Cervantes, Blanch \& Hermoso 2010). Autors com Berkowitz (1993), Dollard, Doob, Miller, Mowrer \& Sears (1939), Valzelli (1983) i Weisinger (1988) van ser els primers a estudiar com la ira, l'enuig i la frustració són expressats de manera desadaptativa a través de les conductes d'agressió i de violència envers els altres o envers un mateix.

Un tercer són les dificultats en la capacitat d'adaptació a les noves situacions. Les persones amb més dificultats per a acomodar-se $\mathrm{i}$ adaptar-se tendeixen a emprar la conducta violenta i agressiva com a estratègia d'actuació (Einarsen, 2000; Sjöström, Elder, Malm \& Beskow,2001; Cooper \& Swanson, 2002). Aquest factor està relacionat amb el d'actitud i les expectatives establertes en el model de Chappell \& Di Martino (2006).

Un quart factor, relacionat amb l'individu que exerceix la violència, és la valoració del tracte rebut (Beech \& Leather, 2006; Lipscomb, Silverstein, Slavin, Cody \& Jenkins, 2002; Camerino, Estryn-Behar, Conway,Van Der Heijden \& Hasselhorn, 2007). Les llargues esperes, la percepció de ser tractat d'una manera discriminada respecte a d'altres i l'alt grau de frustració perquè la persona atesa no rep la resposta esperada per part del professional són qüestions que es relacionen amb aquest factor de risc. Els sentiments $\mathrm{i}$ la vivència de la situació poden comportar que l'ús de l'acció violenta s'expressi envers el professional (Lipscomb \& Love, 1992).

La diferència entre els dos agents que interactuen (usuari i professional) és un cinquè factor de risc. Segons Foucault (1997), tota relació humana és una relació de poder. Aquesta diferència de poder s'intensifica entre l'usuari i el professional quan el primer se sent vulnerable, té dolor i malestar pel que li està succeint i el segon utilitza paraules tècniques, llenguatge poc clarificador i entenedor i una actitud distant i altiva. L'usuari, davant aquest escenari de desequilibri de poder, utilitza l'acte violent com una manera de compensar aquesta diferència (Cantera, Cervantes \& Blanch, 2008; Yang \& Diefendorff, 2009).

I un sisè factor de risc, relacionat amb l'entorn de treball, és la gestió del temps. Bayés (2001) apunta que una inadequada gestió del temps genera en l'usuari malestar, neguit, incomoditat i comenta que, si a aquesta situació s'hi afegeixen altres elements com la manca d'informació, un temps d'espera prolongat per a saber un diagnòstic poc satisfactori, entre altres, això contribueix a fer que hi hagi un augment de l'ansietat i que la conducta violenta envers el professional sigui més probable (Sjöström,Elder, Malm \& Beskow 2001; McPhaul \& Lipscomb, 2004).

En conclusió, la violència laboral de tipus II és un fenomen existent, multicausal i condicionada per una multiplicitat de factors i situacions de risc. La investigació descriptiva realitzada s'ha orientat a saber l'abast del fenomen, a identificar els factors de risc, i a conèixer l'eficàcia dels programes de prevenció. Avui en dia es desconeixen els factors protectors i, conseqüentment, això en dificulta la prevenció. Amb aquest article pretenem que la societat sigui conscient de la importància d'aquest fenomen, tant desconegut encara i que genera patiment en els professionals que atenen persones vulnerables.

\section{Referències}

Bayés, R. (2001). Psicología del sufrimiento y de la muerte. Barcelona: Martínez Roca.

Beech, B., \& Leather, P. (2006). Workplace violence in the health care sector: A review of staff training and integration of training evaluation models. Aggression and violent behavior, 11(1), 27-43.

Berkowitz, L. (1978). Whatever happend to the frustration-aggression hypothesis?. American Behavioral Scientist, 21, 691-708.

Berkowitz, L. (1993). Aggression: its causes, consequences and control. New York: McGraw-Hill, Inc.

Berrios, M.P. \& López-Zafra, E. (2005). Violencia en el trabajo. Jaén: del lunar.

Bowie, V. Defining violence at work: a new typology. En Gill, M., Fisher,B. \& Bowie, V. (2002). Violence at work: causes, patterns and prevention. Devon: Willan Publishing.

Bulatao, E.Q. \& VandenBos, G.R. (1996). Workplace Violence: Its Scope and the issues. En G.R. VandenBos \& E.Q. Bulatao (Eds.), Violence on the job: Identifying risks and developing solutions. Washington, DC: American Psychological Association.

Cal/OSHA (1995). Guidelines for Workplace Security, Preventing Violence in the Workplace: A Second Conference on Workplace Security. San Francisco: OSHA.

Camerino, D., Estryn-Behar, M., Conway, P.M., Van Der Heijden, B.I. \& Hasselhorn, H.M. (2007). Workrelated factors and violence among nursing staff in the European Next study: a longitudinal cohort study. International Journal of nursing studies, 45(1), 35-50.

Cantera, LM., Cervantes, G., \& Blanch, JM. (2008). Violencia ocupacional: el caso de los profesionales sanitarios. Papeles del psicólogo, 29(1), 49-58.

Cervantes, G., Blanch, JM. \& Hermoso, D. (2010). Violencia ocupacional contra profesionales sanitarios en Cataluña notificada por Internet (2007-2009). Archivos de Prevención y Riesgos Laborales, 13(3), 135-140. 
Chappell, D. \& Di Martino, V. (2006). Violence at work. Third edition. Geneva: International Labour Office.

Cooper, CL. \& Swanson, N. (2002). Workplace Violence in the health sector. Geneva: ILO.

Dollard, J., Doob, L., Miller, N., Mowrer, O.H. \& Sears, R. (1939). Frustration and aggression. New Haven, Conn: Yale University Press.

Ekblom, B. (1970). Acts of violence by Patients in Mental Hospital. Stockholm: Scandinavian University Press.

Einarsen, S. (2000). Harassment and bullying at work: A review of the Scandinavian approach. Aggression and violent behavior, 5(4), 379-401.

Eurofound (2012). Fifth European Working Conditions Survey. Luxemburg: Publications Office of the European Union.

Foucault, M. (1997). Historia de la locura en la época clásica. Mèxic: Fondo de Cultura Económica.

Gerberich, S.G., Church, T.R., McGovern, P.M., Hansen, H.E., Nachreiner, N.M., Geisser, M.S., ...Watt G.D. (2004). An epidemiological study of the magnitude and consequences of work related violence: the Minnesota Nurses' Study. Occupational and Environmental Medicine, 61, 495- 503.

Gill, ML., Bowie, V. \& Fisher, B. (2002). Violence at Work. Causes, patterns and prevention. Devon: Willan Publishing.

Krug, E. (Eds.) (2002). World Report on Violence and Health. Geneva: World Health Organization.

Linaker, O.M. \& Bush-Iversen, H. (1995). Predictors of imminent violence in psychiatric inpatients. Acta Psychiatrica Scandinavica, 92(4), 250-254.

Lipscomb, J. \& Love, C. (1992). Violence towards health care workers: an emerging occupational hazard. American Association of Occupational Health Nurses, 40, 219-228.

Lipscomb, J., Silverstein, B., Slavin,T.J., Cody, E. \& Jenkins, L. (2002). Perspectives on legal strategies to prevent workplace violence. The Journal of law, medicine \& ethics, 30 (3), 166-172.

McPhaul, K.M. \& Lipscomb, J.A. (2004). Workplace violence in health care:recognized but not regulated. The Online Journal of Issues in Nursing. Recuperat el 28 de gener de 2015, http://www.nursingworld.org/ MainMenuCategories/ANAMarketplace/ANAPeriodicals/OJIN/TableofContents/Volume92004/No3Sept04/ViolenceinHealthCare.asp

Merecz, D., Rymaszewska, J., Móscicka, A., Kiejna, A. \& Jarosz-Nowak, J. (2006). Violence at the workplace -a questionnaire survey of nurses.European Psychiatry, 21, 442-450.

National Occupational Health and Safety Commission (NOHSC) (1999). Program One Report: Occupational violence. Paper discussed at the 51st Meeting of the Australian National Occupational Health and Safety Commission, 10 March 1999, Hobart.

Neuman, J.H. \& Baron, R.A. (1998). Workplace Violence and Workplace Aggression: Evidence concerning specific forms, potential causes and preferred targets. Journal of Management, 24(3), 391-394.
Nordin, H. (1993). Occupational Injury Information System (ISA). Stockholm: Swedish

National Board of Occupational Safety and Health.

OMS \& OIT (2002). Directrices marco par afrontar la violencia laboral en el sector de la salud. Programa conjunto sobre la violencia laboral en el sector de salud. Ginebra: OMS.

Organización Internacional del Trabajo (OIT) (1998). La violencia en el trabajo: un problema mundial. Organización Internacional del Trabajo. Recuperat el 4 de juliol de 2014, a http://www.ilo.org/global/aboutthe-ilo/press-and-media-centre/press-releases / WCMS_008502/lang--es/index.htm

OIT/ CIE/ OMS/ ISP. (2002). Directrices marco para afrontar la violencia laboral en el sector de la salud. Programa conjunto sobre la violencia laboral en el sector de salud. Ginebra: Organización Internacional del Trabajo/ Consejo Internacional de Enfermeras/ Organización Mundial de la Salud/ Internacional de Servicios Públicos.

Occupational Safety and Health Administration (OSHA) (1996). Workplace violence awareness and prevention: Facts and information. Part I. Washington DC: United States Department of Labour.

O'Leary-Kelly, A. M., Griffin, R. W. \& Glew, D. J. (1996). Organization-motivated aggression: A research framework. Academy of management review, 21(1), 225253.

Paoli, P. \& Merllié, D. (2003). Third European survey on working conditions. European Foundation for the Improvement of Living and Working Conditions. Recuperat el 12 de juliol de 2014, a http://www.eurofound. europa.eu/pubdocs/2001/21/en/1/ef0121en.pdf

Parent- Thirion, A., Fernández, E., Hurley, J. \& Vermeylen, G. (2007). Fourth European Working Conditions Survey. Dublin: European Foundation for the Improvement of Living and Working Conditions.

Plante, E. (2005). Pistes et obstacles en prévention de la violence interne au travail.

Recuperat el 4 de juliol de 2014, a http://www.cgsst. com/stock/fra/doc265-862.pdf

Rippon, T. J. (2000). Aggression and violence in health care professions. Journal of advanced nursing, 31(2), 452-460.

Rumsey, M., Foley, E., Harrigan, R. \& Dakin, S. (2007). National Overview of Violence in the Workplace. Australia: Royal College of Nursing.

Sjöström, N., Elder, D.N., Malm, U. \& Beskow, J. (2001). Violence and its prediction at a psychiatric hospital. European Psychiatry, 16, 459-465.

Toscano, G. \& Weber, W. (1995). Violence in the workplace. Washington DC: US Department of Labor Statistics.

Valzelli, L. (1983).Psicobiología de la agresión y la violencia. Madrid: Alhambra.

Van De Griend, KM. \& Messias, DKH. (2014). Expanding the Conceptualization of Workplace Violence: Implications for Research, Policy, and Practice. Sex Roles, 1-10.

VandenBos, G. R. \& Bulatao, E. Q. (1996). Violence on 
the job: Identifying risks and developing solutions. American Psychological Association.

Vidal-Martí, C. \& Pérez-Testor, C. Patient assaults on professionals? Type II workplace violence: A known phenomenon in Barcelona nursing homes. Work, pendent de publicació,2014. doi: 10.3233/WOR141948

Warshaw, L.J. \& Messite, J. (1996). Workplace violence: Preventive and interventive strategies. Journal of Occupational and Environmental Medicine,38(10), 9931006.

Weisinger, H. (1988). Técnicas para el control del comportamiento agresivo. Barcelona:Martinez Roca.

Wynne, R., Clarkin, N. Cox, T. \& Griffiths, A. (1997). Guidance on the prevention of violence at work. Brussels: European Commission.

Yang, J. \& Diefendorff, J.M. (2009). The relations of daily counterproductive workplace behavior with emotions, situational antecedents, and personality moderators: a diary study in Hong Kong. Personnel Psychology,62,259-295.

\section{¿El paciente agrede al profesional? La violencia laboral de tipo II: un fenómeno existente}

Resumen.Este artículo de carácter descriptivo tiene como finalidad exponer un fenómeno existente como es la violencia laboral. La violencia laboral, un constructo con pocos años de estudio, tiene una incidencia en todas las profesiones y diferentes categorías profesionales. Se estructura en cinco apartados. En el primero, se define propiamente el objeto de estudio; los datos del alcance del fenómeno se presentan en el segundo; en el tercero, la tipología; las teorías que explican el porqué se produce en el cuarto. En el quinto, se presentan los factores de riesgo que pueden incidir en la violencia laboral de tipo II, la violencia que ejercen las personas enfermas, mayores y otros colectivos vulnerables hacia los profesionales que los atienden.

Palabras claves: agresión, profesionales, violencia laboral, vulnerabilidad 